\title{
ANÁLISE DE FATORES PROTETORES E DE RISCO PARA O DESENVOLVIMENTO DE TRANSTORNO MENTAL COMUM EM ESCOLARES DO ENSINO MÉDIO
}

Calos Alexandre Mesa de Souza, Anderson Paulo Silva, Maria Clara Pontes Martins Soares, Aline Aparecida Buriola

Universidade do Oeste Paulista - UNOESTE, Presidente Prudente, SP. E-mail: cmcarlosmesa99@gmail.com

\begin{abstract}
RESUMO
Considerando as múltiplas transições na adolescência, a enfermagem possui papel importante na promoção de ações de valorização e vínculo através de intervenções de assistência prestada no sofrimento psíquico. A escola integra essas promoções em fazer com que o estudante aprenda o que se vive fora dela, com um olhar constante voltado a sociedade, apresentando as experiências da convivência em grupo. Identificar situações ou eventos que desencadeiam sintomas ansiosos e depressivos em jovens escolares. Foi realizada uma pesquisa transversal do tipo quantitativa com 84 estudantes regularmente matriculados no ensino médio integral de um colégio público do município de Presidente Prudente. $O$ instrumento de coleta de dados foi um questionário elaborado pelos próprios autores, e os mesmos foram analisados pela estatística descritiva, sendo apresentados em forma de frequência absoluta e relativa. Os resultados apontaram que as situações de serem avaliados em públicos e aquelas vividas pela primeira vez desencadeiam o fator ansioso, já a família e os relacionamentos são apontados nas situações que oferecem tristeza e depressão. O estudo buscou ressaltar o compromisso da importância do enfermeiro quanto ao trabalho na equipe multiprofissional e escola no conhecimento de lidar com diferentes situações e visando o compromisso terapêutico.
\end{abstract}

Palavras-chave: adolescentes; transtornos mentais; saúde mental; enfermagem psiquiátrica; vulnerabilidade social.

\section{ANALYSIS OF PROTECTIVE AND RICK FACTORS FOR THE DEVELOPMENT OF COMMON MENTAL DISORDES IN HIGH SCHOOL STUDENTS}

\begin{abstract}
Considering the multiple transitions in adolescence, nursing has an important role in promoting actions of appreciation and bond through assistance interventions provided in psychic suffering. The school integrates these promotions in making the student learn what is lived outside of it, with a constant look at society, presenting the experiences of living together in a group. To identify situations or events that trigger anxious and depressive symptoms in young students. A transversal quantitative survey was carried out with 84 students regularly enrolled in a public high school in Presidente Prudente municipality. The data collection instrument was a questionnaire prepared by the authors themselves, and they were analyzed by descriptive statistics, being presented in absolute and relative frequency form. The results showed that the situations of being evaluated in public and those experienced for the first time trigger the anxious factor, while the family and relationships are pointed out in situations that offer sadness and depression. The study sought to emphasize the commitment of the nurse to the importance of working in the multiprofessional team and school in the knowledge of dealing with different situations and seeking therapeutic commitment.
\end{abstract}

Keywords: tennagers; mental disorders, mental helth, psychiatric nursing; social vulnerability. 


\section{INTRODUÇÃO}

A adolescência é considerada a fase em que separa a vida infantil da adulta, sendo o momento em que se manifestam as transformações biopsicossociais. Segundo o Estatuto da Criança e do Adolescente (ECA) considera-se adolescente o indivíduo entre os doze e dezoito anos de idade ${ }^{1}$. Para a Organização Mundial da Saúde (OPA/OMS), a fase da adolescência é compreendida entre dez e dezenove anos de idade. A mesma é diversificada entre juventude e adultos jovens, sendo, quinze e dezenove anos e entre e vinte e vinte quatro anos, respectivamente ${ }^{2}$.

A fase da adolescência é demarcada por transformações biopsicossociais as quais levam o indivíduo ao aumento das responsabilidades sociais, a consecução de diferentes padrões comportamentais, além do progresso da sua autoestima, desenvolvimento de autonomia e aquisição de competência ${ }^{3}$. Na tentativa de conquistar sua identidade, $\mathrm{o}$ adolescente se depara com situações de maior vulnerabilidade que são comuns nesta fase da vida por ser a etapa caracterizada pela aceitação de alguns padrões sociais, onde os mesmos são instigados a testarem suas capacidades diante de impasses, sendo frequentes as situações que levam ao adoecimento mental ${ }^{4}$.

Diante das transformações marcantes da adolescência surge o Transtorno Mental Comum, descrito por sintomas depressivos, com situações de ansiedade, excitabilidade, apresentando outras queixas como insônia, fadiga, dificuldade de concentração e memória ${ }^{5}$. Usualmente o TMC apresenta sintomas ansiosos e depressivos acompanhado de queixas somáticas. Ele afeta a população de dessemelhantes faixas etárias, manifestando também na infância e adolescência, sendo menos específica e mais grave nessas fases, pois, tal transtorno provoca prejuízo na convivência social e no rendimento escolar ${ }^{6}$.

A ansiedade também é prejudicial na convivência social e no rendimento escolar no período da adolescência, devido a frequente sensação desagradável que acarreta o sentimento de antecipação de um perigo, próximo ou futuro, provocando uma interpretação diferente da situação. Entretanto até certo grau de sua incidência o medo e ansiedade são entendidos como não patológicos e até possuem um importante fator de proteção na continuidade da raça humana. Os sintomas de ansiedade na fase da adolescência frequentemente são resultados de uso de substâncias desencadeadoras e/ou inadaptação ao contexto escolar ou social ${ }^{7}$ sendo frequente dentro dos acometidos situações de suicídio que conforme dados epidemiológicos demonstram que cerca de 3.590 adolescentes morreram no ano de 2010 vítimas do autoextermínio ${ }^{8}$.

Estudos com a população adolescente que avaliaram TMC, apontaram a associação com uma pior condição socioeconômica, já em outro trabalho realizado na Etiópia, evidenciou que o risco era aumentado quando viviam em família onde as mulheres eram as chefes da casa, ou existia uma baixa escolaridade. De forma com que esses adolescentes eram adequados a sociedade, constatou a redução de TMC ${ }^{9}$.

Outra situação destacada é a automutilação além de considerar uma questão de saúde pública é necessário o acompanhamento ao adolescente para a garantia de um desenvolvimento saudável ${ }^{10}$.

A OMS destaca que a automutilação seguida de suicídio caracteriza um problema de saúde pública mundial, estimando que o suicídio esteja entre as três principais causas de morte de pessoas com idade entre 15 e 44 anos e a segunda principal causa de morte em indivíduos de 10 e 24 anos de idade. Já no Brasil, o estado do Rio Grande do Sul concentra os maiores índices de suicídio com oito a dez em cem mil habitantes ${ }^{11}$.

O prejuízo resultado de um potencial transtorno mental no período escolar acarreta no jovem uma incapacidade de interação social, interfere nas relações entre os mesmos ou com os professores, o desempenho intelectual também fica prejudicado o que dificulta o progresso em sua rotina social ${ }^{12}$.

Considerando a necessidade de intervenção e as atuais conjunturas de assistência prestada ao adolescente, a enfermagem possui um papel relevante devido sua preconização de existência em todos os níveis de assistência, além de promover ações de acolhimento, valorização da pessoa, formação do vínculo, atendimento em situações de sofrimento e reconhecimento das vulnerabilidades o que torna uma ferramenta importante na articulação com os demais profissionais da equipe ${ }^{13}$.

No ambiente escolar, a enfermagem desenvolve suas atribuições, através do papel de 
educador estando apto para impulsionar a qualidade de vida, estando objetivado a fortalecer habilidades de autocuidado evitando as formas de dependência, sendo dessa maneira um aliado aos adolescentes nesta fase de transição ${ }^{14}$. Como hipótese de estudo acredita-se que a pontos de vulnerabilidades apresentando ao menos um fator estressante de prevalência o respeito por regras impostas pelos responsáveis e pouca capacidade de proteção.

Este estudo tem objetivo de identificar situações ou eventos que desencadeiam sintomas ansiosos e depressivos em jovens escolares.

\section{MÉTODOS}

Realizou-se um estudo quantitativo, de carácter transversal para avaliação de fatores protetivos e estressores em adolescentes em período escolar e sua relação com sintomas depressivos e ansiosos.

A amostra compõe-se por 84 adolescentes matriculados em uma escola pública de ensino médio em modalidade integral, no ano letivo de 2019. Foram excluídos os alunos acima de 18 anos, os que não aceitarem participar da pesquisa e aqueles que não responderem corretamente os questionários, tornando a resposta ambígua ou incompreensível.

Para a coleta de dados, utilizou -se o seguinte instrumento:

Questionário sociodemográfico (QSD) desenvolvido pelos pesquisadores contendo as seguintes variáveis independentes: fatores que desencadeiam ansiedade, tristeza, situações de tristeza e ansiedade e fatores protetores e de alívio. O processo de aplicação dos instrumentos realizou-se pelas seguintes etapas: em visita agendada à escola foi entregue o material de pesquisa para os alunos que levaram para suas casas para análise e assinatura dos responsáveis legais; em momento posterior, aqueles que tiverem o TCLE assinado e o QSD preenchido pelos pais, responderam aos outros instrumentos em sala de aula, de maneira individual, na presença do pesquisador e após as devidas orientações. Aceitaram participar da pesquisa 85 adolescentes, porém, 5 destes $(5,9 \%)$ foram excluídos por não cumprirem os critérios de inclusão referente a idade.

Os dados foram analisados de forma descritiva e estão apresentados em forma de frequência absoluta e relativa. As questões aplicadas aos voluntários permitiam múltiplas respostas, desta forma a soma das frequências excedem a totalidade de respondentes, uma vez que estes, em sua maioria, estes optaram pela escolha de mais de uma alternativa. As análises foram realizadas com o auxílio do software $R$.

$O$ estudo foi realizado mediante cadastro na Coordenadoria de Pesquisa, Desenvolvimento e Inovação (CPDI) da Universidade do Oeste Paulista (UNOESTE), sob o número no 5494. Obteve aprovação do Comitê de Ética em Pesquisa em 06/08/2019. Obteve protocolo da Plataforma Brasil CAAE: 14287119.0.0000.5515. A pesquisa cumpre todas as normas éticas vigentes na Resolução №: 466/2012. Para tanto, foi aplicado aos participantes da pesquisa um Termo de Assentimento (TA) e um Termo de Consentimento Livre e Esclarecido (TCLE).

\section{RESULTADOS}

Sobre o perfil dos estudantes da escola pública do ensino médio integral, 84 participaram do estudo, a média de idade foi de $15.83 \pm 0.84$ anos, destes $61,25 \%(n=49)$ do sexo feminino e $38,75 \%(n=31)$ do sexo masculino. Com relação ao estado civil dos participantes $77,5 \% \quad(n=62)$ estão solteiros e 22,55 ( $n=18$ ) estão namorando. No que se refere a renda familiar dos indivíduos, $1,25 \%(n=1)$ recebe até 500 reais mensais e $26,2,5 \%(n=21)$ até 2000 reais por mês.

Outras informações como a porcentagem de alunos que pretendem concluir o ensino médio e quantos deles exercem algum trabalho remunerado após o horário de aula, a qualidade do ensino e a importância da função social que a escola apresenta, além da papel dos responsáveis interferem no processo decisório dos jovens, implicando nas diferentes situações apresentadas a seguir.

A tabela 1 destaca em distribuição o percentual dos fatores que desencadeiam os sintomas de ansiedade, onde 58 (69.0\%) entrevistados responderam que ser avaliado em público é um fator desencadeante de ansiedade.

Avaliações em público são enfrentadas com muita dificuldade pelos jovens, pois tem uma insegurança maior em relação aos adultos, principalmente por saber que estão sendo avaliados, seja dentro do âmbito escolar ou fora, sempre tem a sensação de estarem sendo avaliados.

Como segundo fator desencadeante de sintomas de ansiedade, estão as provas. Os jovens se preocupam com a escolha profissional 
que vem após a conclusão do ensino médio, com as exigências do contexto em que vivem como grupo de pares, família, escola e vestibulares e suas próprias demandas, por isso a incidência de estresse e sintomas de ansiedade. Estes fatores prejudicam o desenvolvimento sociocognitivo do estudante, pois a rotina acadêmica exige um elevado desempenho e concentração de esforços.

Tabela 1. Distribuição percentual dos fatores que desencadeiam sintomas de ansiedade - Presidente Prudente, 2020.

\begin{tabular}{lll}
\hline Fator Ansiedade & $\mathbf{n}$ & $\mathbf{\%}$ \\
\hline Ser avaliado em público & 58 & 69.0 \\
Provas & 57 & 67.9 \\
Locais muito cheios & 41 & 48.8 \\
Locais fechados & 28 & 33.3 \\
Situações que causam medo & 47 & 56.0 \\
\hline Total de respondentes & $\mathbf{8 4}$ & $\mathbf{1 0 0 . 0}$ \\
\hline
\end{tabular}

A figura 1 apresenta a distribuição em percentual das situações que desencadeiam múltiplas sensações. $71,4 \%$ dos estudados responderam que situações que são vivenciadas pela primeira vez expressam ansiedade, preocupação, inquietação, irritação, cansaço ou insônia.

Em relação à vivência inédita de diversas situações é inevitável a promoção em todos os indivíduos de sintomas que advém ou se assemelham a ansiedade, entretanto, em relação aos jovens e considerando sua baixa resiliência no enfrentamento/impactos das situações vividas pode haver um aumento da intensidade desses sintomas e sendo comum nesta fase a vivência de novas situações se torna comum que seja apontada como principal fator desencadeante.

Figura 1. Distribuição percentual de fatores de ansiedade, preocupação, inquietação, irritação, cansaço ou insônia - Presidente Prudente, 2020.

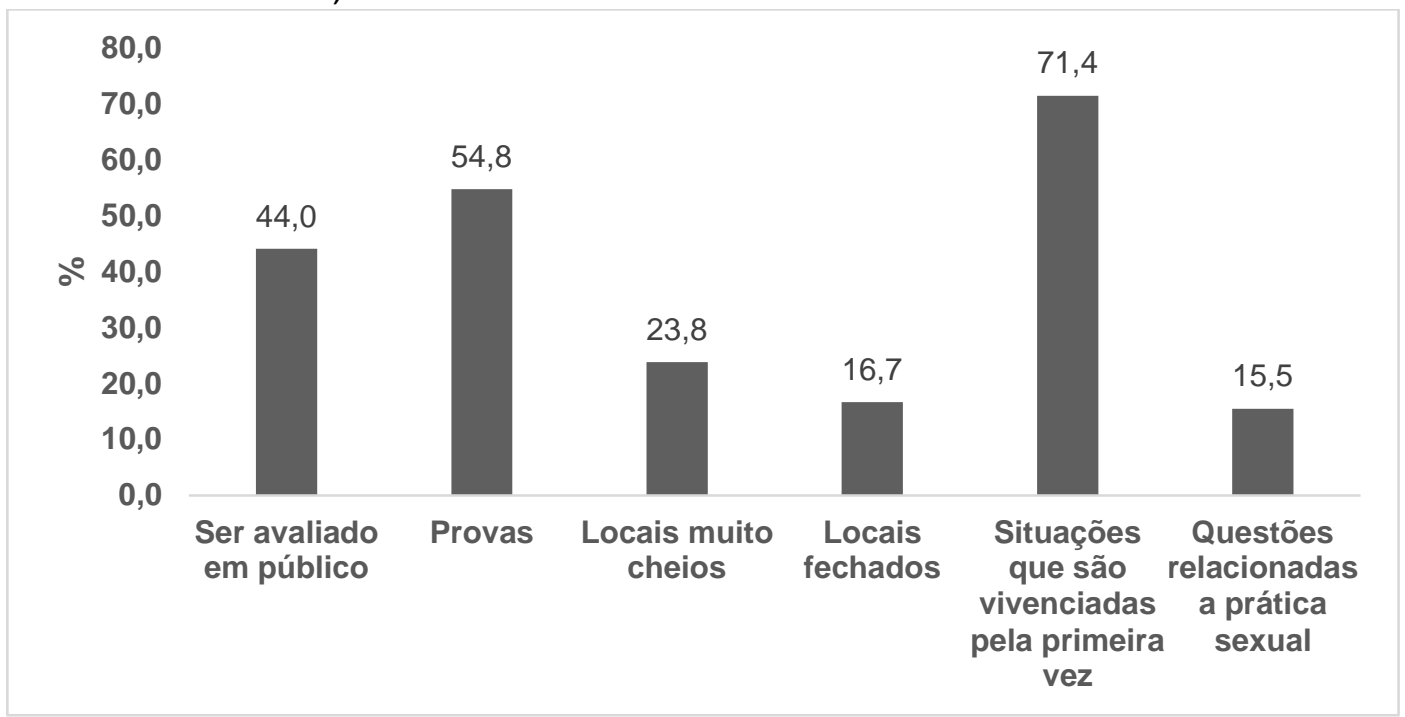

Sobre os fatores que desencadeiam tristeza, desânimo, falta de energia ou interesse, fadiga, falta de vontade e pensamento negativos, $56(76.7 \%)$ dos pesquisados destacaram o relacionamento como principal fator, seguido de família (60.3\%).

As inúmeras dúvidas que tangem o âmbito do relacionamento durante a adolescência, questões de sexualidade e de 
necessidade de conquista de território provocam as turbulências no relacionamento com o outro, conforme demonstrado nas tabelas 2 e 3 e consequentemente as novas estruturações sobre família e as fragilidades nos indivíduos pertencentes provocam desarranjos em sua rotina o que destaca a família como segundo fator com maior número de apontamentos sobre os entrevistados.

Tabela 2. Distribuição percentual de fatores que desencadeiam tristeza, desânimo, falta de energia ou interesse, fadiga, falta de vontade e pensamentos negativos - Presidente Prudente, 2020.

\begin{tabular}{lll}
\hline Fator Tristeza & $\mathbf{N}$ & $\mathbf{\%}$ \\
\hline Família & 44 & 60.3 \\
Relacionamento & 56 & 76.7 \\
Sexualidade & 10 & 13.7 \\
Drogas & 7 & 9.6 \\
Religião & 5 & 6.8 \\
\hline Total de respondentes & $\mathbf{7 3}$ & $\mathbf{1 0 0 . 0}$ \\
\hline
\end{tabular}

O fator relacionamento aparece novamente em primeiro lugar (74.6\%) quando os estudantes foram questionados sobre os fatores que desencadeiam tristeza, desânimo, cansaço ou pensamentos negativos. Em seguida o fator família também se apresenta em 39 (54.9\%) dos entrevistados.

Tabela 3.Distribuição percentual de fatores de tristeza, desânimo, cansaço ou pensamentos negativos Presidente Prudente, 2020.

\begin{tabular}{lrr}
\hline Tristeza & $\mathbf{n}$ & $\mathbf{\%}$ \\
\hline Família & 39 & 54.9 \\
Relacionamento & 53 & 74.6 \\
Sexualidade & 3 & 4.2 \\
Drogas & 4 & 5.6 \\
Religião & 6 & 8.5 \\
\hline Total de respondentes & $\mathbf{7 1}$ & $\mathbf{1 0 0 . 0}$ \\
\hline
\end{tabular}

A seguir são apresentados os fatores considerados protetores para sintomas de ansiedade e depressão. Para a maioria dos entrevistados (75.9\%) responderam que os momentos de lazer com os amigos/família aliviam estes sintomas. Um pouco atrás apresenta 0 fator manter relacionamentos saudáveis (62.7\%).

Este resultado condiz com o que foram percebidos nos jovens pesquisados, eles demonstraram que se sentem à vontade quando estão com os amigos, assim, podem se expressar e demonstrar seus sentimentos sem julgamentos, isso evita pensamentos tristes e de angustias.

Manter um relacionamento saudável com a família e amigos ampara o jovem, pois, nesta fase eles expressam dificuldades de emitir seus sentimentos. 
Figura 2. Distribuição percentual de fatores considerados protetores para sintomas da ansiedade e depressão - Presidente Prudente, 2020.

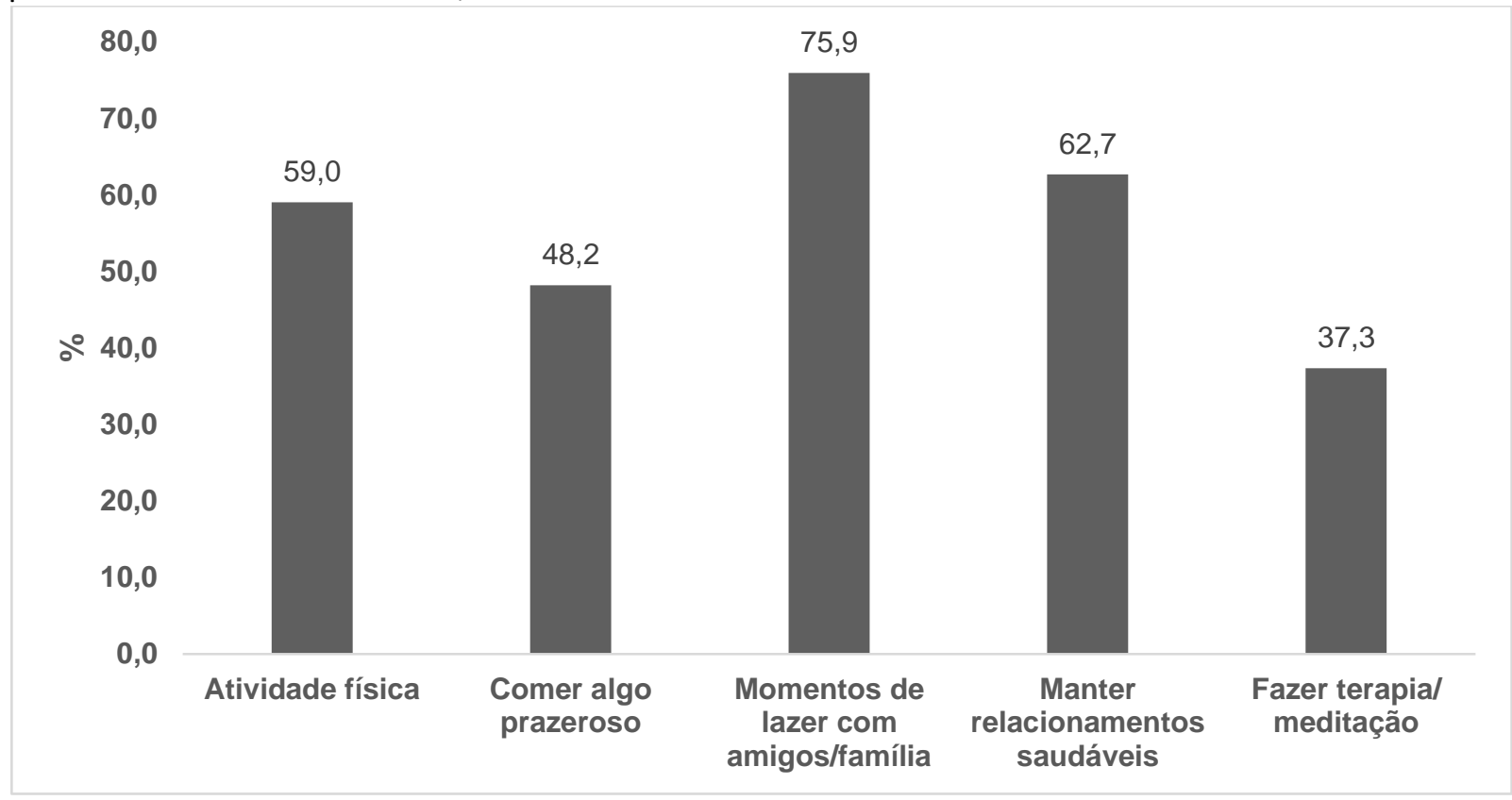

Para os fatores que aliviam ansiedade e/ou tristeza, $75.5 \%$ dos pesquisados responderam que realizar terapia/meditação amenizam essas situações. $61,9 \%$ dos entrevistados respondem momentos de lazer com amigos/família, ficando em seguida.

Terapia e meditação são fatores que aliviam situações de ansiedade e tristeza. Poucos estudantes tem acesso à terapia e meditação por conta da dificuldade no acesso destas atividades. De fato, a terapia e a meditação ajudam a evitar que apresentem sintomas de ansiedade e tristeza, pois é um momento que podem expor seus sentimentos e pensamentos, tanto para o terapeuta como para si próprio, aliviando os sintomas de ansiedade e tristeza.

Figura 3. Distribuição percentual de fatores que aliviam situações de ansiedade e/ou tristeza - Presidente Prudente, 2020.

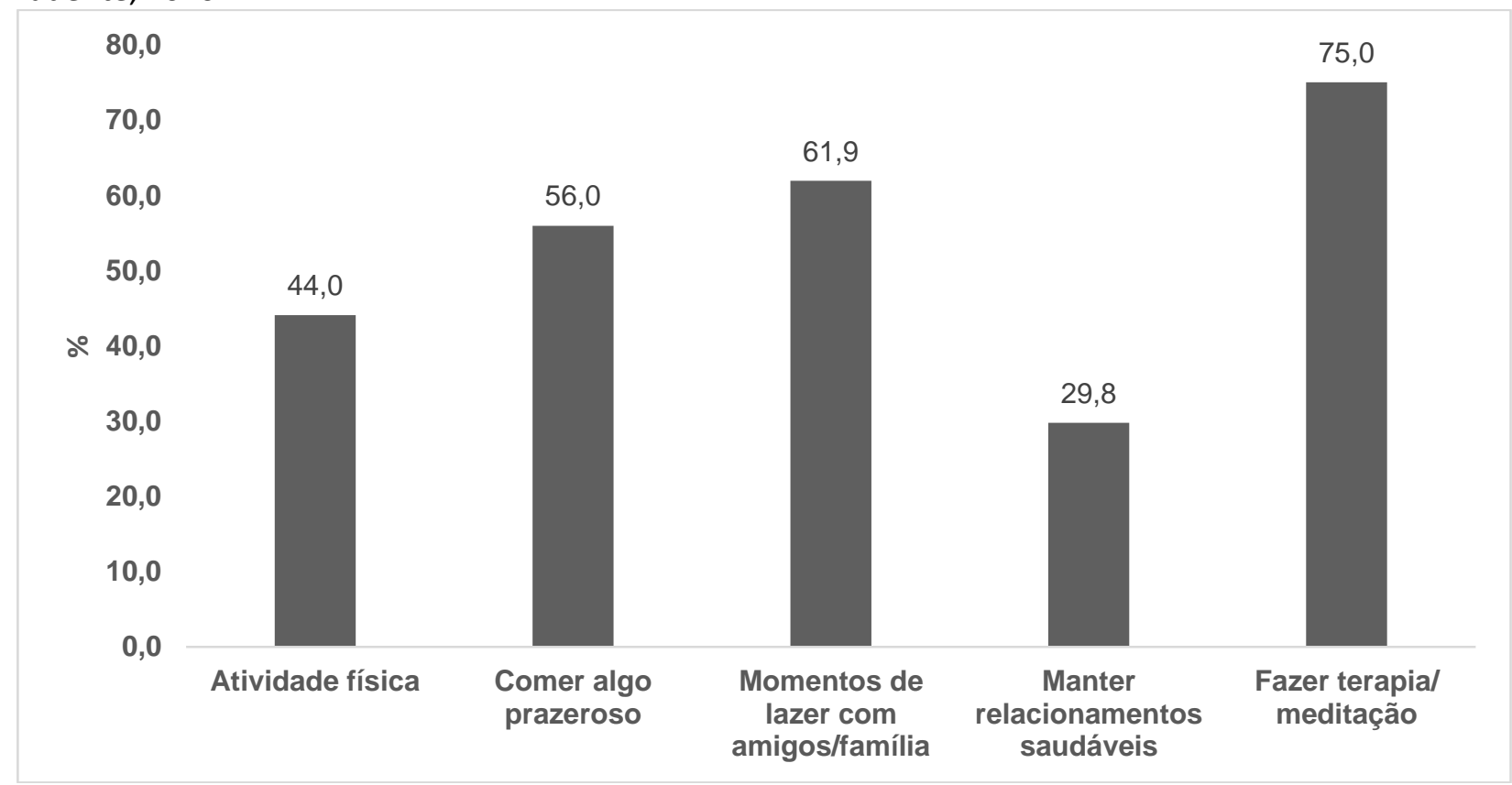




\section{DISCUSSÃO}

O indivíduo entende a prova como um instrumento de avaliação e desempenho uma forma de intimidação pessoal, com um sentimento de falha antecipado, por medo do fracasso ${ }^{15}$.

Todas as mudanças enfrentadas pelo adolescente impactam em sua nova relação com o mundo, essa nova fase tem como caraterísticas as perdas, ou seja, a perda do corpo e da identidade infantil. Portanto o adolescente que vive todos estes processos se encontra com uma nova imagem formada e essa é a grande função da adolescência, uma busca incessante por uma nova identidade sendo perceptível a grande dificuldade que pais, professores e sociedade têm em lidar com o tema relacionamento na adolescência bloqueando fontes que poderiam ser uma forma segura para esclarecer suas dúvidas e quando ocorrem são carregadas de preconceitos, repressões e tabus. Desta forma o assunto relacionamento como fator de risco está destacado nos resultados como principal situação, pois, as fontes sanadoras das dúvidas estão despreparadas para atender a necessidade do adolescente, portanto, é necessárias atividades assistenciais que configurem ações para a juventude e que esteja apta para organizar de forma interdisciplinar a necessidade de apoio ao adolescente ${ }^{16}$.

O contexto familiar atual é baseado em estruturas com novos papéis e diferentes maneiras de relacionamento, entretanto a família ainda é vista como construtora dos laços afetivos e a formadora do eixo moral do indivíduo, sendo essas características a definição do grupo familiar e a união entre os membros. Os novos conceitos e as novas modalidades de família impulsionam as situações conflituosas que surgem como desigualdades da própria família ou até mesmo pelo convívio social se o ambiente familiar for frágil provavelmente todos os indivíduos sentiram os impactos dessa fragilidade, principalmente em indivíduos na fase da adolescência ${ }^{17}$.

Diante disto, é importante destacar que o contexto onde o adolescente está inserido tem grande importância no seu desenvolvimento, inclusive a família desempenha um papel importante no exercício de suas funções de proteção. Entretanto, podem existir falhas neste contexto desta forma resultando em um fator de risco para o desencadeamento de vários transtornos mentais a curto, médio e longo prazo, desta forma o resultado e os apontamentos da família como segundo maior fator de risco é importante destacar a necessidade de apoio integral a família, partindo da premissa que neste contexto está a base para a formação do indivíduo ${ }^{18}$.

Fatores protetores são aspectos pessoais e/ou ambientais que dão sustentação aos jovens nos desafios da vida. Autonomia, autoestima, bem-estar subjetivo, competência emocional, afetos positivos, apoio social, coesão familiar, são alguns dos exemplos de fatores de proteção. Como fatores protetores individuais estão os perfis psicológicos (otimismo, autoestima, esperança, bem-estar) são responsáveis para o progresso pessoal saudável. O que se refere aos aspectos ambientais, um bom suporte familiar e social é um importante fator protetor, ajudando no aumento da autoestima e bem-estar físico e psicológico ${ }^{19}$.

O tratamento para depressão e ansiedade é realizado preferencialmente com medicações, que apesar de terem um efeito satisfatório trazem consigo os efeitos colaterais e a dependência. A terapia é considerada um apoio no tratamento contra depressão e ansiedade podendo facilitar nas questões de medo e problemas de relacionamentos interpessoais ${ }^{20}$.

A meditação é uma possibilidade benéfica para um aprimoramento pessoal saudável e um comportamento de maior eficiência, desfocando a atenção através de locomoção da consciência do mundo exterior para o interior ${ }^{21}$.

O autoconceito demora a se desenvolver por meio de vivencias e convívios com a sociedade. Os adolescentes que passam por situações desagradáveis, como maus tratos e negligencia, por adultos que são importantes em sua história de vida, tendem a florescer um autoconceito não valorizado a respeito de si. No contexto escolar vivenciado pelos estudantes, podem surgir sintomas de ansiedade frente às dificuldades de aprendizagem, desempenho escolar, regras a serem respeitadas e motivação 22 .

Após a análise dos resultados, foram identificados que as situações de serem avaliados em público e as situações que são vivencias pela primeira vez desencadeiam os sintomas de ansiedade, preocupação, inquietação, irritação, fadiga, cansaço ou insônia. 
Família e Relacionamentos aparecem como principais fatores para o desenvolvimento de tristeza, desânimo, falta de energia ou desinteresse, fadiga, falta de vontade e pensamentos negativos.

Para os fatores protetores de ansiedade, tristeza e depressão são fazer terapia/meditação e momentos de lazer com amigos/ família.

Destaca-se alguns aspectos limitantes desta pesquisa, o número pequeno da amostra, a dificuldade de acesso à escola para coleta de dados, a adesão por parte dos alunos, pais e responsáveis, a falta de compreensão no momento de resposta do questionário o que permitiu respostas ambíguas e a exclusão deste dado do resultado final. Além do mais, o estudo possui um desenho transversal, o que não permitiu uma leitura longitudinal ou causal entre as variáveis.

O estudo na área de saúde mental ressalta o compromisso da importância do enfermeiro quanto ao trabalho na equipe multiprofissional, favorecido com o conhecimento de lidar com diferentes situações e visando o compromisso terapêutico. Também tem como objetivo a preservação e a promoção da saúde mental, intervindo nas situações leves e graves.

Como devolutiva para os participantes da pesquisa, após a análise dos dados, foi realizada uma palestra com orientações sobre sintomas depressivos e ansiosos e condições relacionadas. Em momento posterior a palestra, os alunos foram atendidos individualmente com a devolutiva dos resultados encontrados pela pesquisa e receberam orientações sobre os sinais de risco das doenças e onde procurar ajuda.

Os autores declaram não haver qualquer potencial conflito de interesse que possa interferir na imparcialidade deste trabalho científico.

\section{REFERÊNCIAS}

1. Estatuto da Criança e do Adolescente ECA (1990). Ministério da Justiça: Lei Federal no. 8069/1990. Diário Oficial da União. Poder Executivo, Brasília - DF;

2. Auerbach RP, Alonso J, Axinn WG, Cuijpers $P$. Mental disorders among college students in the World Health Organization World Mental Health Surveys [published correction appears in Psychol Med. 2017 Nov;47(15):2737].
Psychol Med. 2016;46(14):2955-2970. https://doi.org/10.1017/\$0033291716001665

3. Pinto AVL, Cavalcanti JG, Araújo LS, Coutinho ML, Coutinho MPL . Depressão e adolescência: relação com qualidade de vida e bem-estar subjetivo. Rev. Psicol. IMED, Passo Fundo, v. 10, n. 2, p. 6-21, dez. 2018. Disponível em <http://pepsic.bvsalud.org/scielo.php?script=sci_ arttext\&pid=S2175-

$50272018000200002 \& \operatorname{lng}=p t \& n r m=i s o>$. acessos $\begin{array}{llll}\text { em } & 27 & \text { jul. } & 2020 .\end{array}$ https://doi.org/10.18256/21755027.2018.v10i2.2752

4. Aviero MN. Resiliência em adolescentes religiosos. Revisão. Faculdade de Medicina da Universidade de Lisboa. Lisboa - PT. 2016; DOI: http://hdl.handle.net/10451/28969

5. Parreira BDM, Goulart BF, Haas VJ, Silva SR, Monteiro JCS, Gomes-Sponholz FA. (2017). Transtorno mental comum e fatores associados: estudo com mulheres de uma área rural. Revista da Escola de Enfermagem da USP, 51, e03225. https://doi.org/10.1590/s1980-

\section{0x2016033103225}

6. Lemos P, Marback RF. Depressão Infantil e Impactos no Desenvolvimento do Indivíduo. XV SEPA - Seminário Estudantil de Produção Acadêmica, UNIFACS, 2016. Disponível em: https://revistas.unifacs.br/index.php/sepa/article /view/4347

7. Grolli V, Wagner MF, Dalbosco, SNP. Sintomas Depressivos e de Ansiedade em Adolescentes do Ensino Médio. Revista de Psicologia da IMED. 2017.9 9(1), 87-103.

https://doi.org/10.18256/2175-

5027.2017.v9i1.2123

8. SILVA L. Suicídio entre crianças e adolescentes: um alerta para o cumprimento do imperativo global. Acta paul. enferm., São Paulo , v. 32, n. 3, p. III-IVI, jun. 2019 . Disponível em $<$ http://www.scielo.br/scielo.php?script=sci_artt ext\&pid=S0103-

$21002019000300001 \& \operatorname{lng}=p t \& n r m=i s o>$. acessos em 27 jul. 2020. Epub 29-Jul-2019. https://doi.org/10.1590/1982-0194201900033 
9. Ribeiro IBS, Correa MM, Oliveira G, Cade NV. Common mental disorders and socioeconomic status in adolescents of ERICA. Revista de Saúde Pública [online]. v. 54; São Paulo 2020 Epub 07jan-2020 https://doi.org/10.11606/S1518$\underline{8787.2020054001197}$

10. Trinco, ME, Santos JC. O adolescente com comportamento autolesivo sem intenção suicida no internamento do serviço de urgência de um hospital pediátrico da região centro. Revista Portuguesa de Enfermagem de Saúde Mental. 2017 (Spe. 63-68. http://dx.doi.org/10.19131/rpesm.0169

11. Oliveira, MCD, Pacheco ML, Paula JTN, Ramires JZ, Silva MS, Fitaroni JB. Suicídio na adolescência: um estudo a partir da psicologia do desenvolvimento. Tcc-psicologia, 2020; file:///C:/Users/Dell/Downloads/476-1424-1PB\%20(2).pdf

12. Lima NM, Carvalho DLS, Ramalho RAVL, Lins MAF. Características do Transtorno de Ansiedade em Meio Acadêmico e Escolar: Uma Revisão Integrativa da Literatura. Id on Line Rev.Mult. Psic., Outubro/2019, vol.13, n.47, p. 1236-1251. ISSN: 1981-1179; https://doi.org/10.14295/idonline.v13i47.2131

13. Armstrong KR, Souza AM, Sneddon PL, Potts JE, Claydon VR, Sanatani S. Exercise and the multidisciplinary holistic approach to adolescent dysautonomia. Acta Pediatric, 2017. 106: 612618. https://doi.org/10.1111/apa.13750

14. Silva LLT, Alvim CG, Costa CC, Ramos TM, Costa EE. Adolescent Suicide In Brazilian Nursing Publications: An Integrative Literature Review. R. Enferm. Cent. O. Min. 2015 set/dez; 5(3):18711884;

https://core.ac.uk/download/pdf/268201913.pdf

15. Gonzaga, LRV. Enfrentando provas escolares: relações com problemas de comportamento e rendimento acadêmico no Ensino Médio. [tese] PUC- Campinas Campinas, p. 1-259, 2016.

16. Costa, JF, Pacheco ZML, Silva GA. Compreendendo a sexualidade dos Adolescentes: REME - Rev. Min. Enf, São Paulo, v. 11, n. 2, p. 188-195.

https://cdn.publisher.gn1.link/reme.org.br/pdf/v

\section{1n2a13.pdf}

17. Sales ET. A influência do contexto familiar na saúde mental das crianças e adolescentes. IX Semana Acadêmica e III Seminário estadual de serviço social. Vol. I - Ano 2016 ISSN 2446-5518; http://itecne.com.br/social/edicoes/2016/artigos Artigo\%20\%284\%29.pdf

18. Patias ND, Silva DG, Dell'aglio DD. Exposição de adolescentes à violência em diferentes contextos: relações com a saúde mental. Temas psicol., Ribeirão Preto, v. 24, n. 1, p. 205-218, mar. 2016. http://dx.doi.org/10.9788/TP2016.1$\underline{14}$

19. Cardoso HF, Borsa JC, Segabinazi JD. Indicadores de saúde mental em jovens: fatores de risco e de proteção. Est. Inter. Psicol., Londrina , v. 9, n. 3, supl. 1, p. 325, Dec. 2018. https://doi.org/10.5433/22366407.2018v9n3suplp03

20. Baleotti ME. Efeitos da atividade física na ansiedade e depressão: uma revisão bibliográfica. XI Fórum Científico Fema - Anais. Fundação Educacional do Município de Assis (FEMA)- ISSN 2446-4708, 2018;

21. Ferreira FM, Pompeu NBM, Ferreira DS, Ramos LAS, Leite TSA. Os benefícios da meditação no tratamento do transtorno de ansiedade: uma revisão sobre o tema. I encontro dos cursos de enfermagem da universidade estadual do maranhão [anais]. Babacal - MA. 2019; $\quad$ file:///C:/Users/Dell/Downloads/2029Arquivo\%20de\%20Anais-13732-1-1020191014\%20(1).pdf

22. Silveira JA, Santos WC, Paschoal RA, Moraes, RCP. Ansiedade em alunos do ensino médio: um estudo de revisão. Psicologia.pt. ISSN 1646-6977. 2020;

https://www.psicologia.pt/artigos/textos/A1379. pdf 